\title{
New Dimensions in Seismic Data Interpretation with 3-D Virtual Reality Visualisation for Burst-Prone Mines
}

\author{
P.K. Kaiser, P. Vasak, F.T. Suorineni MIRARCO - Mining Innovation/Geomechanics Research Centre, Laurentian University, Canada \\ D. Thibodeau INCO Technology Centre, INCO Limited, Canada
}

\begin{abstract}
3-D virtual reality (VR) visualisation has opened new opportunities for complex $3 D(x, y, z), 4 D(x, y, z, t)$ or even nD data interpretation. The integration of $3 D$ geologic data, $3 D$ excavations and stress information, $1 D$ time or mine sequencing and $n D$ seismic event parameters into a common mining process model provides a platform for experts in various fields to better design, evaluate, monitor and modify mine plans throughout a mine's life; from feasibility, through operation, to closure. Viewing seismic data in a stereoscopic VR environment within a mining process model offers data interpretation processes previously unavailable at lower dimensionality. MIRARCO has developed data analysis and viewing processes specifically designed to enhance microseismic and seismic data interpretation in a collaborative, immersive VR environment; bringing mine personnel and expert consultants together to evaluate data and make strategic decisions for cost effective and safe mining. The focus of this paper is on understanding seismicity from a mine safety and mine planning perspective. The resultant benefits of innovative seismic data interpretation are reduced production costs and enhanced workplace safety.
\end{abstract}

\section{EVOLUTION OF VIRTUAL REALITY TECHNOLOGY}

Making sense from huge amounts of complex data with unknown patterns and multiple interrelated parameters is a challenging task that requires tools to detect patterns and trends. The human mind is highly developed to use visual perception in every day life. Hence, it is imminently obvious that there should be a potential in exploiting this ability for complex, multi-dimensional data processing using scientific visualisation (www.ncsa.uiuc.edu). Scientific visualisation enables data to be presented in dynamic images in order to reveal intrinsic patterns and dependencies. Scientific visualisation was made possible by high performance computing and computer graphics starting in the 1970's. This evolution was the brainchild of Douglas Engelbart in the 1950 's who first envisioned that computers should not just be used for number crunching but as tools for digital display. The idea gradually transformed computer graphics to produce virtual reality (VR) environments, as we know them today. Virtual reality is the result of a demand for interactivity in computer visualisation.

VR applications started in the military for real time display of radar defence systems data. Pioneering industries in the use of $3 \mathrm{D}$ visualisation are the aerospace, automotive and biomedical industries (Tyler 2003). The oil industry pioneered the use of VR in the earth sciences and reservoir engineering fields. The late application of $3 \mathrm{D}$ visualisation in the oil and gas $(O \& G)$ industries is attributed to the lack of suitable software to drive these large environments in interactive data analysis (Zeitlin, 2003). An international consortium was established by the O\&G industry in 1998 (Schlumberger et al., 2002) to demonstrate the impact of VR for the industry. A first prototype of VR for the O\&G industry was available in late 1998 (Fröhlich and Göbel, 1999). The overall goals of the international consortium were to apply and evaluate virtual environment technology for reservoir discovery, for the characterization of oil fields and for the management of oil extraction. MIRARCO recognized the same barriers in the use of VR for the mining industry and embarked on a strategic R\&D program to assist mining in the adoption of VR.
VR environments were also created to enable multidisciplinary collaboration, to generate synoptic views of data from multiple sources and to support strategic planning by multi-disciplinary teams (Fröhlich and Göbel, 1999). The international consortium proved that with VR an "Earth scientist could dive under the surface and fly around a reservoir, detecting interesting features in the data that would be less obvious on a small desktop computer monitor" (Polyakov, 1999) and that multi-disciplinary collaboration was possible. There are many forms of VR (desks, walls to caves, with or without haptics, etc.). However, due to similarities between O\&G and mining applications, MIRARCO opted for collaborative, immersive VR (CIVR) as the most appropriate VR format for mining. With multi-dimensional models different data from various sources can be integrated and interpreted in CIVR by a multi-disciplinary team in a more effective manner than ever before. Most importantly, CIVR accelerates the pace of discovery, improves communication, reduces the risk for error and makes the decision making process more efficient and convincing ("seeing is believing").

Several success stories have been told in the O\&G industry following the use of VR applications. One such anecdotal story stems from the Schlumberger ConocoPhilips Ekofisk field in the North Sea (Norsk Hydro, 2003). In a jack-up drilling campaign involving 5 wells, extensive water influx was observed in the overburden of the first well resulting in the abandonment of the well at $8000 \mathrm{ft}$ sub sea. A second well was successfully drilled after overcoming the same water influx situation but which was successfully controlled with increased mud weight with no loss situation. The next two wells were drilled without encountering the high water pressure situation. An alternative well plan for the first abandoned well was made but also had to be abandoned for the previous reason. Drillers and management were reluctant to make further trials, but giving up the well meant a loss production opportunity, as this was a one time drilling campaign. With the use of VR, team members pooled experiences together using data from various sources in an integrated manner to plan a well trajectory in the overburden 
with little risk of hitting the high-pressure water. The well was successfully drilled yielding revenue of 18 million dollars that otherwise would have been lost.

VR application to science and engineering therefore offers many advantages and benefits:

- Facilitates the use of visual perception, a capability that only humans master

- Enhances ability to integrate complex and/or large volumes of data from different sources

- Provides increased understanding of complex data sets and simplifies critical decision making

- Encourages interdisciplinary team collaboration and brainstorming

- Reduces time in data understanding and interpretation

- Connects geographically remote experts (through linked VR centres) for problem solving at much reduced cost and with great time savings

- Provides a great strategic planning, negotiating and public relations tool based on the principle of "seeing is believing". Management and investors are more easily convinced when they instantly see what they would have to read in lengthy reports, articles or papers.

\section{APPLICATION OF VR IN MINING}

Mines are complex environments and solving mining problems require an integrated approach. Mines collect data from exploration to recovery and closure; including data from boreholes, geological mapping, rockmass characterization, rock engineering properties, orebody geometry delineation, excavation and infrastructure layout design, support performance observations, seismicity, costs and much more. Unfortunately, this data is rarely integrated and properly analysed, and as a result, we rarely have a grasp of the larger picture of a mine's performance. By learning how to turn data into information, or by adopting technology to assist in this process, much can be gained as illustrated by the success story of the $O \& G$ industry.

The key for a more efficient use of data is to provide planning and design teams a means to first identify areas where data is either "weak" or missing in order to make decisions, and then to provide a means for fast and effective data integration and processing. This can best be accomplished within a collaborative, immersive visualisation framework where teams of sector experts (geologists, planners, designers, operators, managers and eventually financiers) can work together to gain a real advantage by quickly establishing the 'big picture', resulting from a greater understanding of the data, and thus the value of a property. VR application offers the best opportunity for understanding complex, varied and large volumes of data in a central setting. However, as indicated earlier, the late adoption of VR technology in earth sciences and mining engineering is a result of a lack of suitable, sector-focused tools and processes, as well as a lack of skill in making the technology work for the mining industry. Furthermore, data is not structured and stored for interactive data analysis. Recent development in the software sector (Datamine, FracSIS, GoCAD, etc.) has removed some of these obstacles and has paved the way for the use of VR in mining. For these and other reasons, the mining industry has been late in taking advantage of the VR technology.

Through extensive industry consultation, MIRARCO identified a need for a R\&D program supporting the adoption of VR in mining and with funding from the Canada Foundation for Innovation (CFI, matched by the Ontario Innovation Trust (OIT)) was able to open a state-of-the-art Virtual Reality Laboratory (VRL) (Fig. 1) at Laurentian
University. The VRL constitutes the anchor facility of a multidisciplinary research approach bringing disciplines from exploration to mine site rehabilitation together through a Centre for Integrated Monitoring Technology (CIMTEC). This research program is designed to meet the needs of the mineral exploration, mining and geotechnical industries, and is the first VR facility fully dedicated to the mineral industry sector.

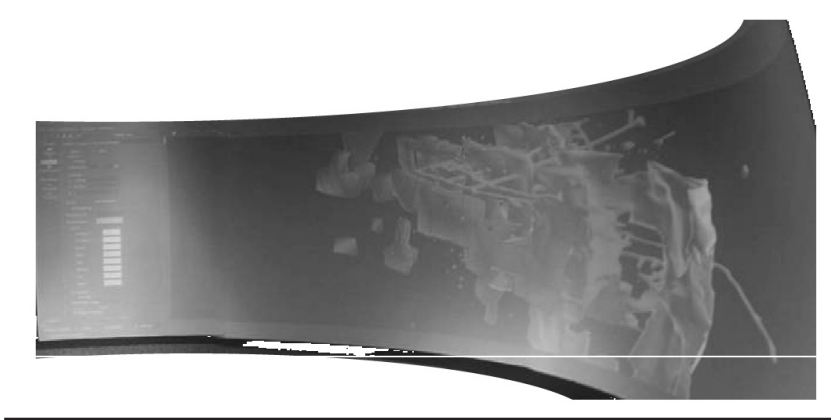

FIG. 1 View of double curved screen with image of mining blocks, drifts and geology used for seismic data interpretation (see FIG. 2)

This facility builds on technologies developed and proven for the O\&G industry. Several visualisation packages are used to "map" data from multiple sources to a single, world coordinate system. The system projects dynamic stereo images onto a $8 \times 22$ foot double-curved screen, providing up to 20 persons with the sense of full data immersion. Subsurface excavations, infrastructure, geology, hydrology, geochemistry, geomechanics, cost and time can all be combined to provide a holistic overview of a mine property. Inherent complexities of three-dimensional data can be viewed with a true sense of depth and spatial relationship. The scale of the screen, combined with the depth perception provides an immersion that increases the participants' overall understanding of spatially complex data relationships and accelerates data comprehension as well as transfer of experience and knowledge.

The power of VR environments lies in the illusion of being in a virtual world and individuals can see and feel their data as being part of it. The large size and extent of images combined with the depth perception in VR centres allow interpreters to see details without losing the broader perspective. Data and images can be rotated in any direction, magnified to various scales and sliced in arbitrary directions for detailed viewing, analysis and interpretation.

The benefits of VR in geomechanics design of underground excavations were presented by Henning et al. (2003). Fig. 2 includes geological data (dyke, waste stringer, orebody), geometry of excavations (stopes and development drifts, stress in voxet with a movable stress plane), stress-driven dilution potential, and seismic data. Even if the image is enlarged, it is practically impossible to interpret and relate this data without stereo VR.

\section{USE OF VR FOR SEISMIC DATA INTERPRETATION}

Data fusion provides a "new" view of existing data. It enhances the identification of hidden relationships or discovery and explanation of complex data interdependencies. Seismic and microseismic data patterns are complex, come in large volumes from several years of seismicity monitoring, and each event involves more than a dozen measured or interpreted parameters (seismic moment, stress drop, source size, location in space and time, etc.). The interpretation of seismic data therefore constitutes one of the most complex forms of mining data and thus requires an integrated approach to data interpretation. Most importantly, proper 


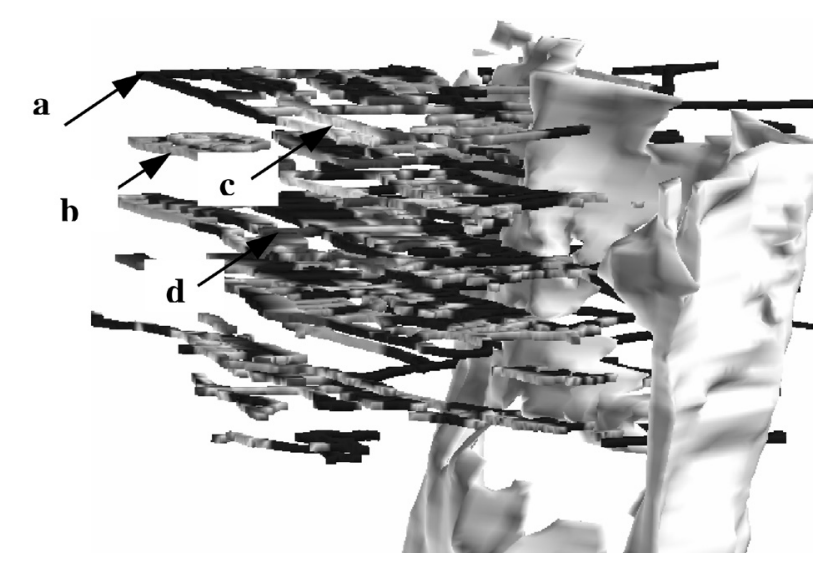

FIG. 2 Integrated data image of mining block (scale: top to bottom about $300 \mathrm{~m}$ )

data interpretation depends on bringing together experts with vastly different backgrounds and expertise, including experts from seismology, geology and structural geology, geomechanics, (geo-) statistics and mining engineering. Collaborative, immersive VR therefore lends itself ideally for seismic data interpretation.

The Canadian Rockburst Handbook (Kaiser et al.1996) provides the background for understanding of seismicity and its effect on rock support. It also provided a general approach for the development of seismic data interpretation tools for support design in deep level hard rock underground mines. The Rockburst Handbook was the result of a 5-year study of the Canadian Rockburst Research Program (CRRP) funded by the Mining Research Directorate (MRD, CAMIRO and its Canadian and international, industrial sponsors), the Ontario Ministry of Northern Development and Mines and the Natural Sciences and Engineering Research Council (NSERC). The study reviewed worldwide support practices in burst-prone grounds and developed fundamental knowledge for the understanding of seismicity-induced failure mechanisms. An empirical database of rock damage and support performance under actual rockburst conditions was compiled and used to establish important relationships between seismic source magnitude and distance, initial excavation conditions, amount of rockburst damage and predicted support performance. Scaling laws (relationship between seismic source parameters, distance and ground motion) were established for major underground mines in the Canadian Shield. A seismic hazard map concept was developed in the form of Mine Map Overlays (MMO) to project anticipated hazards to mine infrastructure at various development or production levels.

The implementation of this approach was, however, hampered by severe limitations in overcoming the threshold of data integration and interpretation. It was simply too timeconsuming to build realistic geological models, combine them with stress models and superimpose the effect of seismicity (rockmass degradation and dynamic loading) at that time. Now, with advanced computing, data integration and visualisation capabilities in a VR environment, these barriers and obstacles have been removed.

The approach adopted for seismic data interpretation in this paper separately examines the effects of large seismic events (rockbursts) and those of microseismic events (rockmass degradation). Seismic events cause sudden and large scale hazards with immediate consequences whereas microseismicity cause long-term hazards through its cumulative effects in degrading the rockmass due to cumulative rockmass damage.
Understanding seismic events from mining safety and enhanced production point of view enables identification of zones of potential seismic activity and the characteristics of seismic aftershocks. This in turn enables one to estimate consequences of additional loading on mine structures in order to select appropriate support systems based on the level of anticipated hazard and location. Through the power of the VR the Geomechanics Research Centre (MIRARCO) has developed various approaches to interpret seismic and microseismic data patterns. Many of these approaches are supported by plug-ins developed for GoCAD ${ }^{\mathrm{TM}}$ or other software packages.

The power of the VR for the interpretation of seismic data is the ability to display large volumes of data and different types of data in a multi-dimensional form (e.g. event magnitude, damage location, damage intensity (seismic clustering; Falmagne, 2000; Falmagne et al., 1998)) and, most importantly, in time sequence (called time-links below).

\section{NEW DIMENSION IN SEISMIC AND MICROSEISMIC DATA INTERPRETATION}

\subsection{Background}

The results presented in this paper are the outcome of a joint collaboration between INCO Mines Technology Department and INCO's Creighton Mine, and MIRARCO, Sudbury, Ontario. Creighton Mine has been in operation for over 100 years and long-range plans are under review to mine well below the 2,500-m horizon. Associated with this long history of operation and depth are both stress and structurally related seismic activities monitored by a full-waveform Hyperion Microseismic System (ESG, 2000) since November 1995.

Creighton Mine has de-stressing and extraction sequence protocols in place to mitigate stress-induced seismicity such as strain and pillar bursts. The gains of the de-stressing procedure are further enhanced with proactive designs and installed support that minimizes the effects of any dynamic stress-induced events. In general, stress-driven seismicity is well understood and controlled. However, Creighton mine, as most other mines, is significantly affected by discrete geological features as shown in Fig. 3. The influence of these structures, shears, faults and dykes, is complex and less understood, particularly the mine-wide interaction between mining blocks needed to be investigated in more detail.

Experience at the mine, supported with several years of seismic monitoring records, shows that both microseismicity (MS) and seismicity are often located along these discrete, characteristic geological structures (Vasak and Neumann, 1999). Planes of seismic activity include geological "planes of weakness" (e.g., shears, faults, weak contacts and dykes) and features attracting stress (e.g., strong dykes, contacts with stiffness contrast). The role of these geological structures in causing seismicity is poorly understood and they are often only linked to seismic activity after the fact.

There is a need for a better understanding of the interaction among the discrete geological structures (faults and shear zones), ubiquitous joint zones and mining-induced stresses, for both economic and safety reasons. To arrive at a better understanding of the complex stress and structural geology conditions at the mine, the microseismically active structures had to be identified in space, from the vast microseismic records accumulated at the mine over the years, and the time sequence in activating zones of seismic activity had to be understood.

Large magnitude events are often interpreted as fault-slip events along pre-existing structures. This interpretation may be valid for some of the observed events when these events are clearly associated with large-scale geological structures, as is typical for earthquake scenarios. However, in mining, 


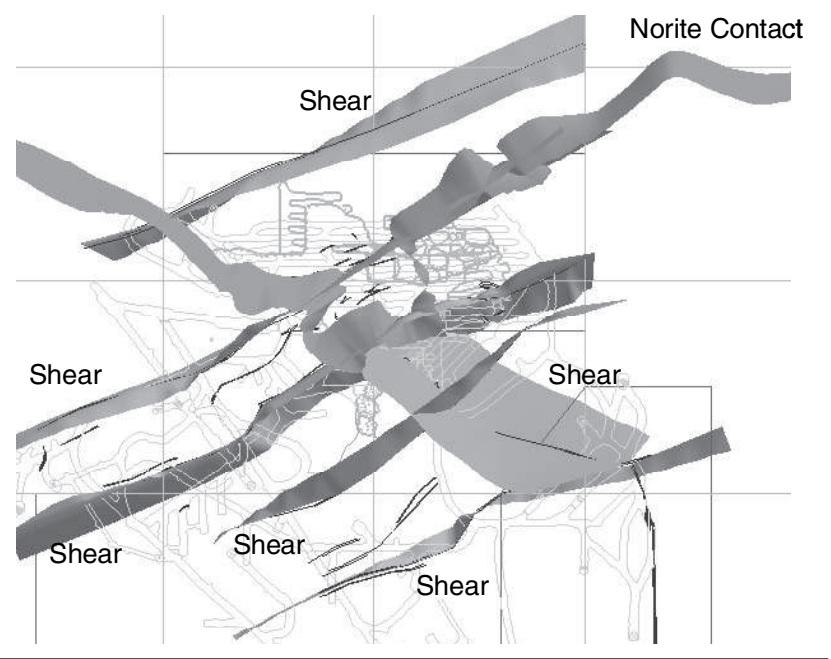

FIG. 3 Major geological structures at Creighton Mine (Vasak et al., 2004)

such structures are often created gradually as mining creates degrees of freedom for movements along weakness planes. Hence, microseismicity may be associated with smaller-scale, non-continuous structures that contain rock bridges. Only after sufficient deformation has accumulated are large-scale features created. Structures, which deviate from the typical fault-slip mechanism model and involves fracture of intact rock, must also be readily identified from the MS data. Details of sources of seismic and microseismic events can be found in Vasak et al. (2004).

In the VRL, we are now able to better examine the evolution of complex and large volumes of seismic and microseismic data and understand the spatial and time evolution better than ever before. The VR technology has enabled us to develop procedures and tools to effectively interpret seismicity and its impact on workplace conditions. This procedure is illustrated by Fig. 4, showing how seismic data is used to identify zones of rockmass damage (volumes of degradation), active planes (planar features of degradation or movement), time evolution (seismic matrix and probability tree), and impact on mine (hazard maps and monitoring); all to enhance work place safety and to assist optimal production decision making.

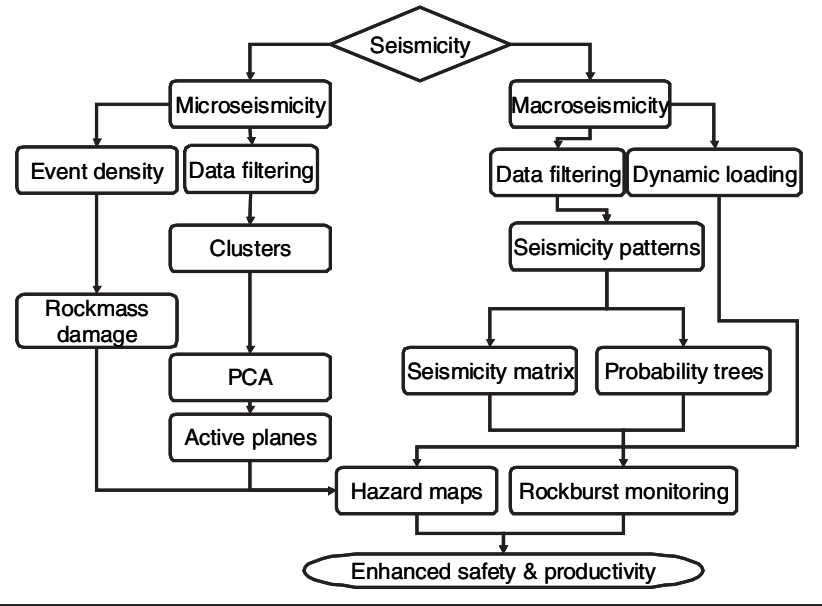

FIG. 4 Procedure for interpretation of seismic and microseismic data (PCA = principal component analysis)

\subsection{Seismic Data Visualisation and Utilisation: Time-link and Probability Trees}

Our interpretation of seismic event sequences presented here is based on the hypothesis that subsequent events may be related, i.e., subsequent seismic events can be "connected in space" and visualized as a time sequence chain. This chain or time sequence vector string is called "Time-links" (Fig. 5).

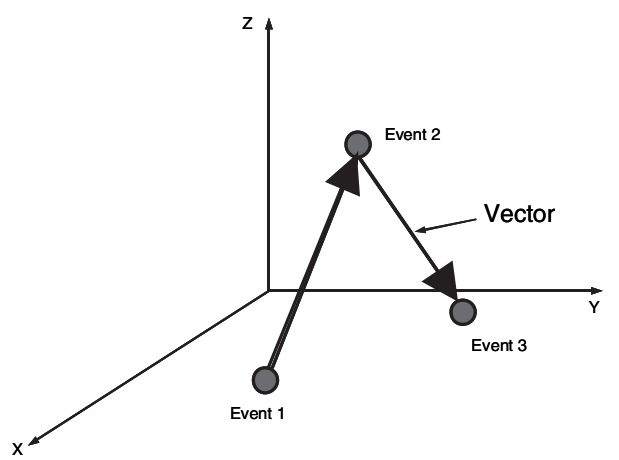

FIG. 5 Time-link concept showing event-connecting vector string

Of course, it is extremely important to disconnect unrelated events, e.g., those that are related to a blast rather than a precursor. To ensure that seismic events are not blast-induced or related, blast events and any seismic events occurring within blasting times are filtered out from the database and not connected (broken links). Connections between events may also have to be broken if there is no physical or geological reason for linkages. Redundant links can be identified by experienced workers such as the ground control engineer at the mine.

Time-links enable tracking of seismic migration patterns and can be related to changes in mining geometry. The timelink concept is used to interpret seismic migration patterns visually as illustrated for a given time window by Fig. 6 .

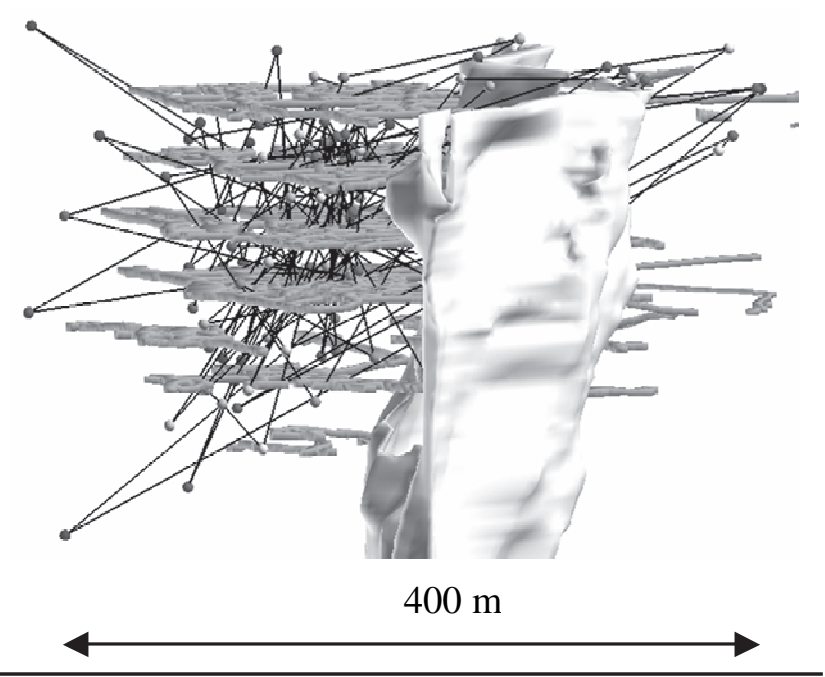

FIG. 6 Time-links showing linkage of stress-induced activity in the immediate stoping area (area with high event density in centre of image) to relatively remote seismicity in hangingwall (left) and behind or inside dyke (right)

In geomechanics, it is often assumed that seismicity is primarily related to stress changes and changing mine geometry (ore extraction). While the seismicity in the hangingwall (Fig. 6) may well be related to stress changes due to mining in an orebody (not shown) on the left side of the developed zone, the seismicity inside or behind the dyke 
is remote $(>100 \mathrm{~m})$ from any mining and cannot be explained by excavation-induced stress changes (the stress change calculated by continuum models at these locations is $<<1 \%$ ). However, cause and effect can be clearly detected by visual inspection of time-link images.

The observed interdependence of seismicity can be attributed to deformation-controlled processes. This can best be understood by a railway analogue. When the locomotive starts to move, cars in the immediate vicinity react while cars at the end of the train do not yet know that the locomotive is moving. They eventually will "get connected" and feel the pull of the engine. The opposite is true when the train decelerates. Similarly, there is a periodic pull-push effect when the extraction ratio in a mine increases. The resulting interaction process is illustrated by the time-links. In other words, the large-scale response of a mine to mining can be effectively visualized even if it cannot be modelled ${ }^{1}$.

We introduced two means to characterize the abovedescribed interaction or "cause and effect" process: (1) seismic migration matrices, and (2) probability trees.

\subsubsection{Time-link matrix}

Fig. 7 shows time-link and seismic migration patterns at Creighton Mine after filtering blast-related and other unrelated events.

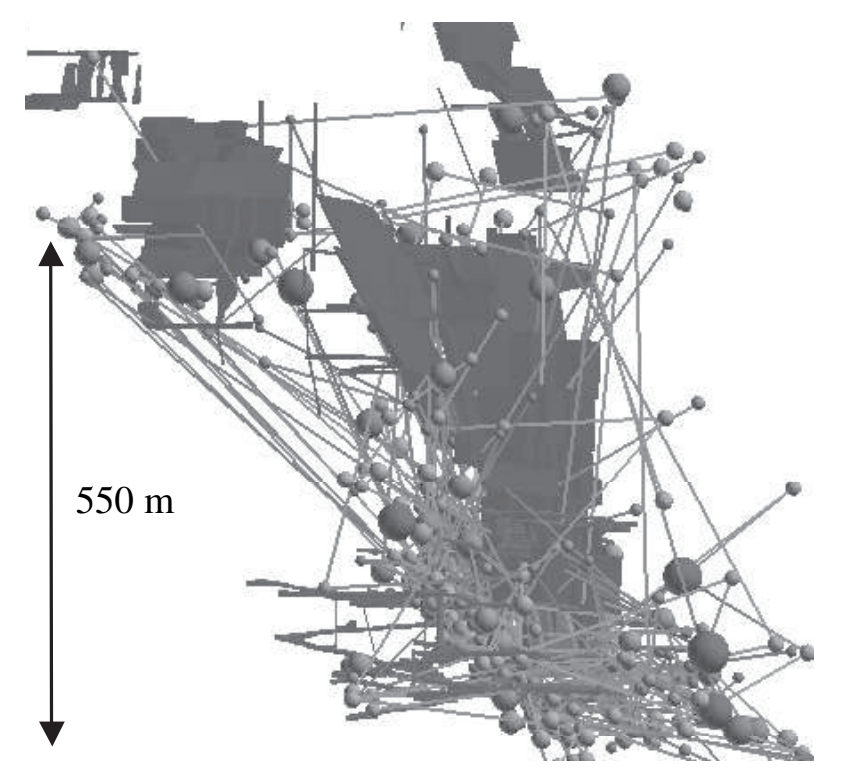

FIG. 7 Seismic migration patterns after filtering blast and other unrelated events (Vasak and Thibodeau, 2003)

A close examination of the seismic data reveals that the mine can be divided into blocks characterized by typical, interrelated seismic migration patterns (Fig. 8). Events migrating within blocks are associated with short inter-event distances and time intervals whereas longer inter-event distances and time intervals characterize inter-block event migration.

Migration of events within and outside blocks can be statistically examined and seismic migration matrices and probability trees established (Table 1 and Table 2$)^{2}$.

A seismic migration matrix is a summary of statistical seismic inter-block activity information. It provides

\footnotetext{
Note: This process cannot be simulated by continuum models; discontinuum models, like 3DEC, could simulate this process but the required block geometry is normally not sufficiently known (see below: active plane detection).

${ }^{2}$ Fields in tables provide number of time-links, interregional probability, distance, delays and anticipated change in magnitude relative to magnitude of event in source block).
}

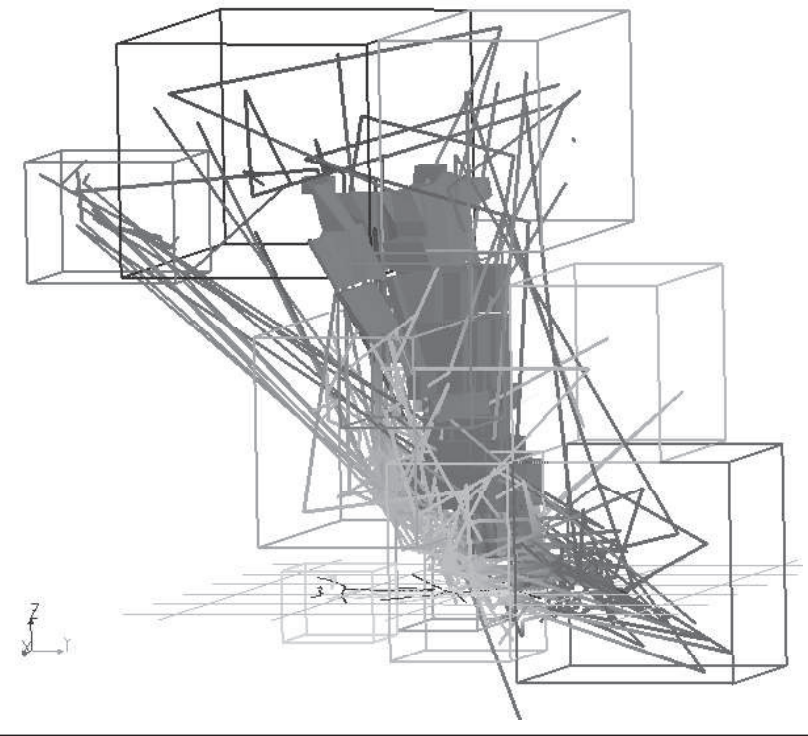

FIG. 8 Seismic blocks based on seismicity migration pattern

TABLE 1 Seismic migration matrix for four seismic blocks; considering events $\geq \mathbf{2 . 2}$ Nuttli magnitude

\begin{tabular}{|c|c|c|c|c|}
\hline $\begin{array}{c}\text { Aftershock Activity } \\
\text { Matrix for Defined } \\
\text { Regions }\end{array}$ & $\begin{array}{l}\frac{\pi}{\#} \\
\frac{y}{0}\end{array}$ & $\begin{array}{l}\text { \# } \\
\text { 듬 } \\
\frac{0}{m}\end{array}$ & $\begin{array}{l}m \\
\# \\
y \\
\frac{0}{m}\end{array}$ & $\begin{array}{l}\# \\
\# \\
\frac{y}{0} \\
\frac{0}{m}\end{array}$ \\
\hline \multicolumn{5}{|l|}{ Block \#1 } \\
\hline Probability & 0.57 & 0.14 & 0.29 & \\
\hline Inter Region Probability & & 0.33 & 0.67 & \\
\hline Distance (feet) & 370 & 1430 & 590 & \\
\hline Delay (hours) & 7.258 & 3.078 & 0.524 & \\
\hline Relative Mn change & -0.95 & -1.50 & -1.15 & \\
\hline \multicolumn{5}{|l|}{ Block \#2 } \\
\hline Probability & & 0.64 & & 0.18 \\
\hline Inter Region Probability & & & & 0.50 \\
\hline Distance (feet) & & 98 & & 622 \\
\hline Delay (hours) & & 0.069 & & 10.253 \\
\hline Relative Mn change & & -0.74 & & -1.05 \\
\hline \multicolumn{5}{|l|}{ Block \#3 } \\
\hline Probability & & & 1.00 & \\
\hline \multicolumn{5}{|l|}{ Inter Region Probability } \\
\hline Distance (feet) & & & 128 & \\
\hline Delay (hours) & & & 4.425 & \\
\hline Relative Mn change & & & -0.85 & \\
\hline \multicolumn{5}{|l|}{ Block \#4 } \\
\hline Probability & & 0.43 & 0.14 & 0.43 \\
\hline Inter Region Probability & & 0.75 & 0.25 & \\
\hline Distance (feet) & & 294 & 138 & 140 \\
\hline Delay (hours) & & 1.308 & 9.756 & 1.429 \\
\hline Relative Mn change & & -0.93 & -1.00 & -0.27 \\
\hline
\end{tabular}

information about anticipated aftershock characteristics such as location in space, distance from main event, delay time and magnitude. An example of a seismic migration matrix is shown in Table 1 . In this example Block 1 and Block 2 have about as many aftershocks within as between other blocks. Block 3 is the most seismically active with $100 \%$ of the time-links within the block. Seismicity in this block has no impact on other parts of the mine. Block 4 shows the highest aftershocks migrating to other blocks (57\%). 


\subsubsection{Probability trees}

Probability trees provide a means for more detailed tracking of seismic event behaviour within and between blocks in the seismic matrix. A probability tree generated for a given seismic block tracks the likely location in space of its aftershock, the distance to aftershocks from the main event, the time-lapse between major event and aftershock, and the probable magnitude of the aftershock. Table 2 is an example of a probability tree for Block 1 of the seismic matrix shown in Table 1. Fields in Table 2 again provide: number of time-links, interregional probability, distance, delay and the anticipated change in magnitude relative to magnitude of the event in the source block.

TABLE 2 Probability tree for seismic Block 1 using events $\geq 1$ Nuttli Magnitude)

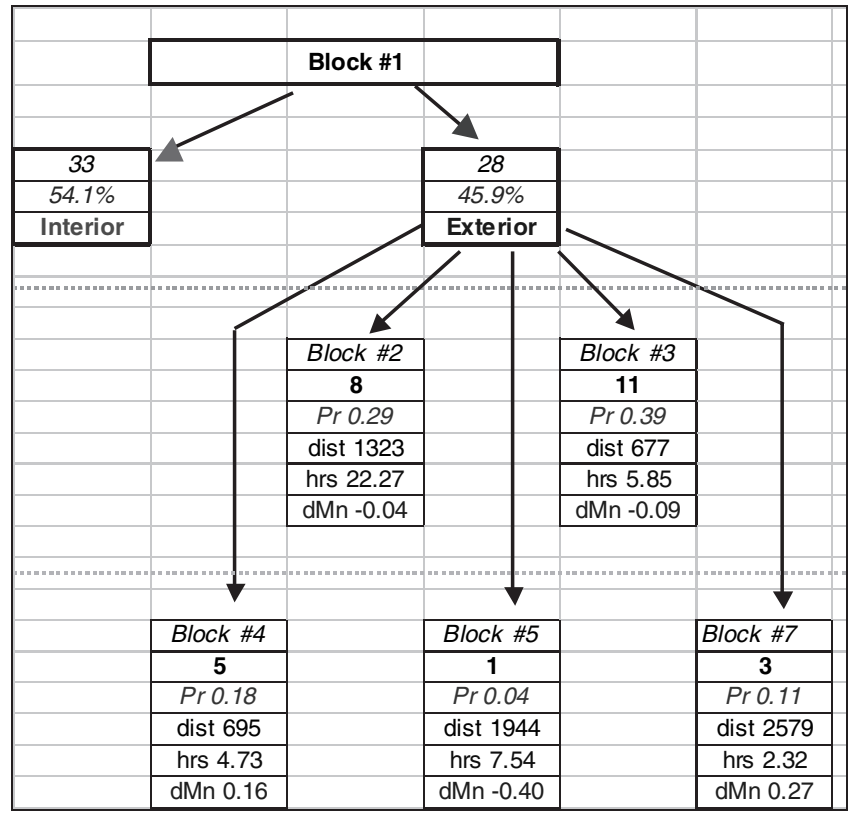

By nature, seismic migration pattern matrices and probability trees identify hazardous work areas in the event of seismic activity based on historical data. They can be used to formulate re-entry policies to enhance worker safety and to support work force allocation during periods of seismic activity as long as data from the past is representative of the future. Hence, seismic pattern matrices and probability trees should be frequently updated and calibrated to remain useful.

\section{SEISMIC HAZARDS}

In underground mining, there are two fundamental hazards to be considered: (1) rockmass degradation due to rockmass damage by microseismic and seismic events, and (2) dynamic loading or shakedown due to seismic wave propagation.

\subsection{Rockmass Degradation due to Microseismicity (MS)}

Such degradation can be diffuse (density increases with time) or along planar features (as seismically active planes develop with time).

The following analysis approach for MS data is based on the hypothesis that MS and seismic events are time and spatially related and occur in natural clusters. Spatial plots of microseismic events, shown as migrating clouds (e.g., Fig. 9), illustrate mining-related stress migration but do not reveal the full impact on the rockmass and on excavation stability unless proper "filtering", data integration and visualisation techniques are used to identify interrelated patterns and trends. Based on research work by Falmagne (2001) on the effect of event clustering and related rockmass damage, we adopt here a novel way of combining space-time event density, agglomerative hierarchical clustering (AHC) and principal component analysis (PCA) in a VR environment for the identification of high-density zones (consequence of cumulative MS effects) and for the identification of planes of microseismic activity (active planes).

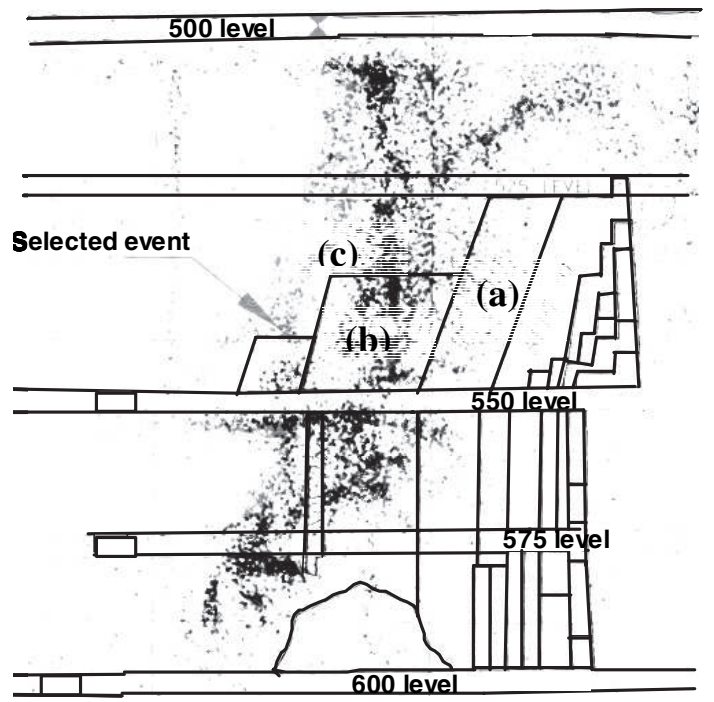

FIG. 9 Unprocessed microseismic data as clouds of points in 3D space evolving during three mining steps ((a) to (b) to (c))

\subsubsection{Diffuse microseismicity - rockmass degradation}

The MS (or crack) density is used to identify areas of rockmass degradation as a result of cumulative damage by MS events. Each microseismic event implies a new crack or extension of an existing crack. Some filtering out of random events (outliers) or events that are due to stress near drifts or other infrastructure may be required to identify mining-induced MS density patterns (particularly, if the primary objective is to examine structurally induced seismicity).

Filtering is also important for the application of the principal component analysis (PCA), a method routinely used in microseismic data analysis. The success of a PCA in defining realistic planes of seismic activity depends on how well natural clusters are identified. In well-defined clusters there should be little or no random objects between them. The presence of random objects between clusters results in chaining or merging of unrelated clusters.

A microseismic density number is assigned to each event and is defined as the number of MS counts in a search sphere of $10-\mathrm{m}$ radius. Events with no neighbours or low number of events (defined by analyst) are dropped (cause no significant rockmass damage). Discrete clusters emerge after the filtering as shown in (Fig. 10). Clusters become more discrete with increasing number of neighbours of events. Discrete clusters identify areas of significant rockmass degradation.

\subsubsection{Identification of seismically active planes}

As indicated above, to understand the time-linkages between internaland remote seismicresponses, it isnecessary toidentify (geological) structures that may transmit deformations over long distances. Seismically active planes (SAP) certainly form part of the rockmass structure that is (currently) being deformed. Hence, identification of such SAPs is important to establish a discontiuum model of a mine. 


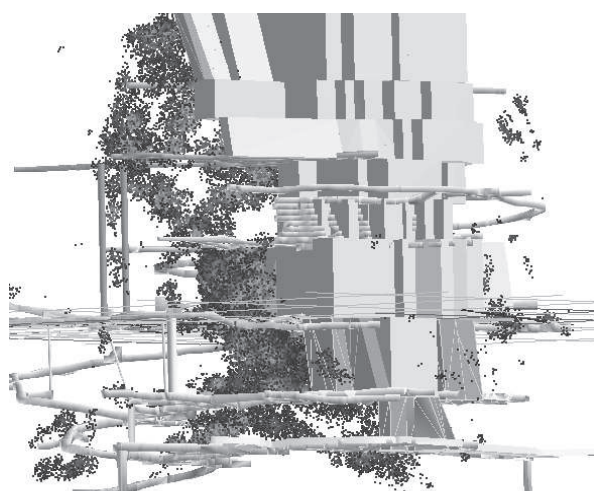

(a) Moderate density filter $>10$ events

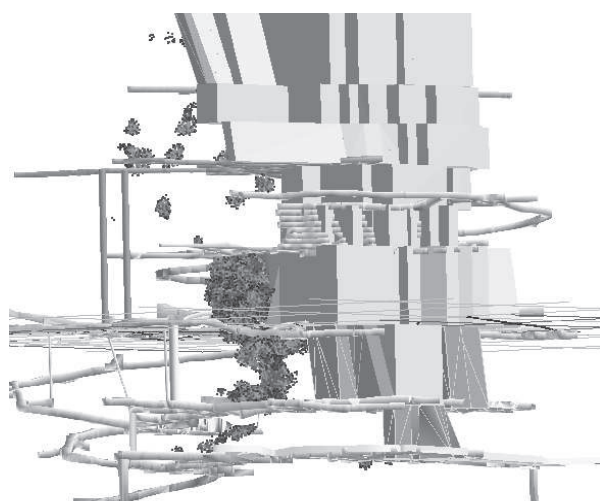

(b) High density filter $>50$ events

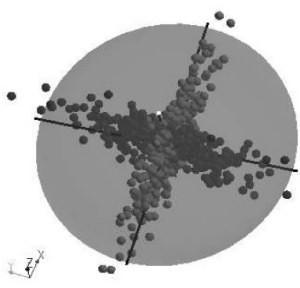

(a) PCA applied to all data fails to define planar features

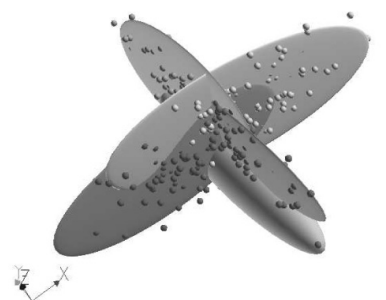

(b) PCA applied after cluster analysis defines two active planes

FIG. 11 PCA and cluster algorithm applied to define active planes

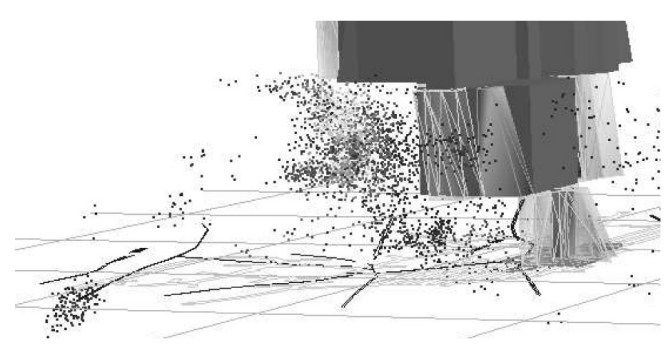

(a) Filtered MS density

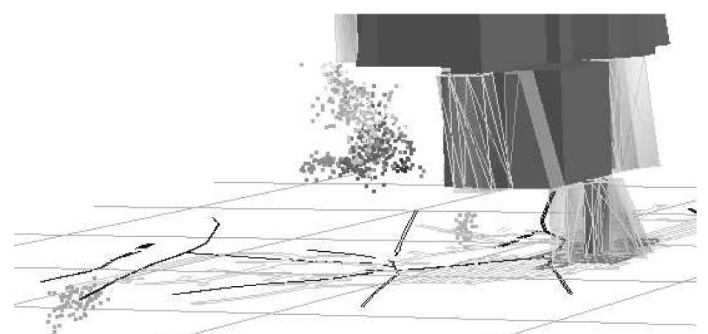

(b) Clusters defined by Ward variance method variables into a smaller number of uncorrelated variables (Johnson and Wichern, 1992). It is based on examining the variance-covariance structure of the data where the first principal component accounts for as much of the variability in the data as possible, and succeeding components account for as much of the remaining variability as possible (Johnson and Wichern, 1992). The application of this method is ideal if there is a good correlation between at least two variables. Poor correlation and large variability in the variables cannot reduce the dimensionality of a data set.

In our context, for a highly scattered MS cloud with no dominant spatial trend, little benefit is gained by doing PCA without pre-processing (cluster identification). As a matter of fact, PCA analysis can be misleading in microseismic data analysis if applied to raw dataset in which planes are not isolated (i.e. planes intersect or are parallel and close to each other). For example, PCA analysis cannot define intersection or closely spaced, sub-parallel, planar clusters. It can also not adequately define the correct planar clusters when chaining (random events between natural clusters) is present due to the tendency of cluster merger.

The application of statistical clustering procedures as pre-processing tools improves the reliability of PCA. This is illustrated Fig. 11.a and b where PCA was first directly applied to data containing two intersecting planar clusters (Fig. 11.a). In this case, PCA sees the two datasets as one and gives one solution that does not represent the data.

After a clustering algorithm (Ward, 1963) was applied to define the two clusters that make up the data, the PCA correctly identifies the two planar features (called activity planes) (Fig. 11.b).

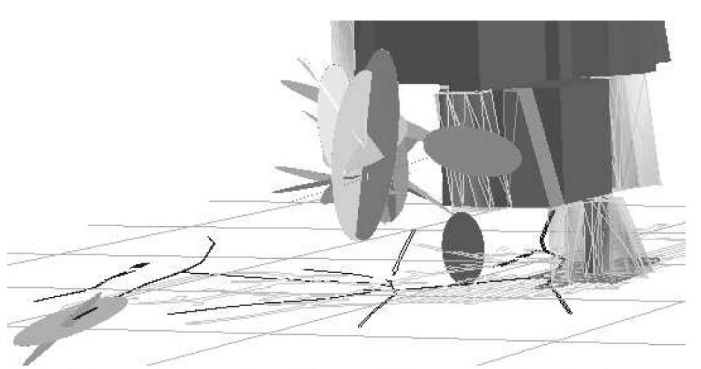

(c) SAPs determined by PCA on defined clusters

\section{FIG. 12 Procedure used to determine representative seismically active planes (SAPs)}

In our research, we adopted hierarchical clustering using the Ward Variance Euclidean (WVE) method to define natural MS clusters (Vasak et al. 2004). WVE was found to be robust compared to other clustering algorithms, i.e., it is less affected by data shape.

An example of SAP determination by applying PCA after cluster analysis is shown in Fig. 12. Only microseismic data from a limited mining block is shown here.

This procedure was subsequently applied to data from an area of the mine where there was concern about future rockburst activity and the resulting 247 SAPs are shown in Fig. 13. This figure highlights how visualisation can be combined with trend detection tools to assist data interpretation (and eventually model building). The general trend of these SAPs was then compared with structures observed and mapped underground in the mine (Fig. 14). 


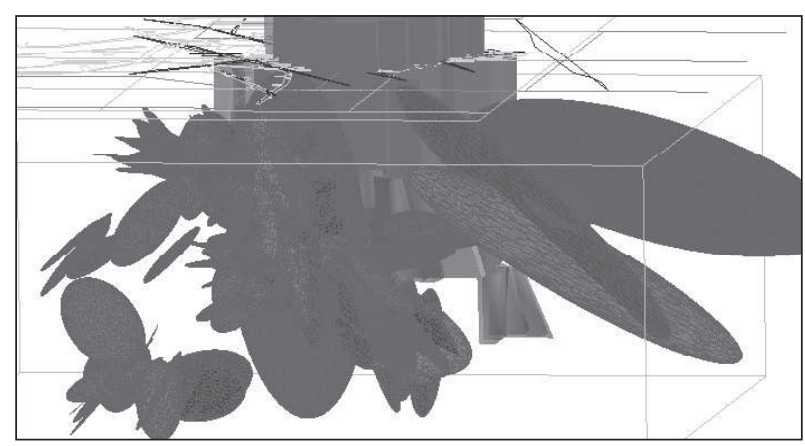

FIG. 13 Seismically active planes determined by PCA on 247 microseismic clusters

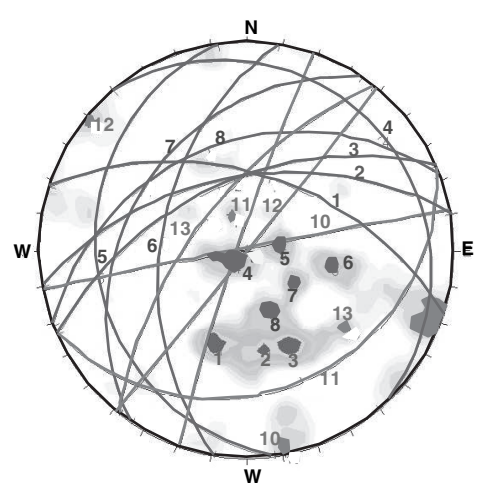

(a) Seismically active planes
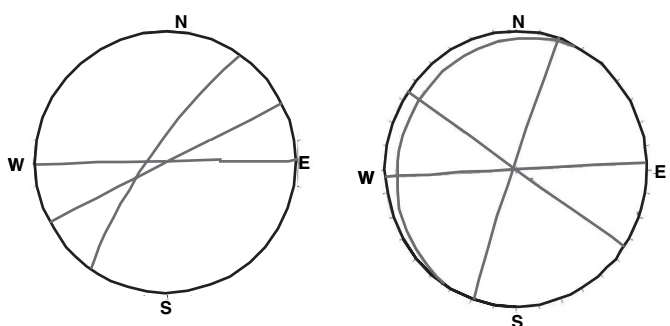

(b) Observed structures and late shears (right)

FIG. 14 Comparison of SAPs and observed structures

Note that not all structures are visible or mapped underground, possibly as a result of scale or lack of access, but most likely because these SAPs do not necessarily consist of single structural features (i.e., they represent echelon fracture systems). Despite these limitations there is a fair correspondence between the seismically active planes determined by the above-described procedure and the observed structures.

\subsection{Damage Caused by Dynamic Loading due to Seismicity}

When a rockburst occurs additional loading in the form of dynamic stress waves are imposed on the walls of mine infrastructure and supports. Marginally stable rockmasses may be induced to fall by dynamic acceleration. Mine structures that were already close to failure (factors of safety close to one) could be triggered to fail by strain bursting or by seismically induced falls of ground as a consequence of this additional loading. The rockmass near structures with higher factors of safety would not fail but the surrounding rockmass will be further damaged and the factor of safety will be reduced.

The consequences of dynamic loading are rockmass fracturing and bulking, as well as shakedown in blocky rockmasses. In the following, we only deal with the effect of dynamic stress (Kaiser et al., 1996; for seismically induced falls of ground refer to same publication). The dynamic farfield stress change modifies the stress near an excavation (by $\Delta \sigma^{d}$ ) causing rotating stress concentrations as shown schematically for a circular excavation by Fig. 15.

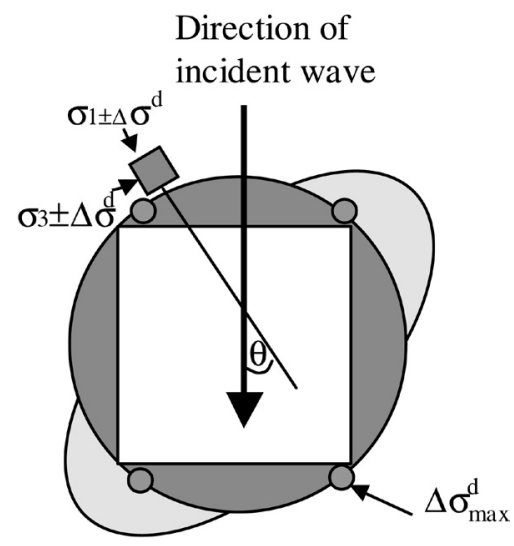

FIG. 15 Superposition of dynamic and static stresses increases overall stresses around excavations in the event of seismicity (Kaiser et al., 1996)

The dynamic stress increment (Eqn 1) can be large if the excavation is close to the epicentre of the seismic event. The maximum dynamic stress increment $\Delta \sigma^{d}$ is given by:

$$
\Delta \sigma^{d}=n c_{s} \rho p p v_{s}
$$

where $c_{s}$ and $p p v_{s}$ are the velocity and peak particle velocity of the shear wave, respectively. The multiplier $n$ depends on the dynamic wave incidence angle: $n=4 \cos 2 \theta$ where $\theta$ is the angle between the direction of the incident wave and any location on the excavation walls $(-4<n<+4)$. Consequently, the maximum dynamic stress increment $\Delta \sigma^{d}{ }_{\max }$ is:

$$
\Delta \sigma_{\max }^{d}= \pm 4 c_{s} \rho p p v_{s}
$$

Taking into account the static stress at the excavation boundary, the resultant maximum stress for a shear wave arriving at an angle $\theta$ is obtained by superposition:

$$
\sigma_{\max }^{(s+d)}=3 \sigma_{1}-\sigma_{3}+n c_{s} \rho p p v_{s}
$$

Since the $p p v$ depends on the magnitude of the event $M_{N}$ and the distance $R$ from the epicentre of the event, the amount of dynamic loading imposed on a mine structure depends on these two factors.

Sharma and Judd (1991) empirically established a relationship between peak ground acceleration $p p a$ at the surface, overburden depth and damage severity using earthquake data from around the world. The amount of damage suffered by a target depends on the intensity of ground motion, which is measured by particle displacement, frequency, $p p a$ or $p p v$. Peak particle acceleration and peak particle velocity are the ground motion measurement parameters commonly used. Peak particle acceleration is related to peak particle velocity. In civil engineering design $p p a$ is traditionally used to design for dynamic loading because building codes (www.eqhazmaps.usgs.gov) describe how much horizontal force a building or other structure should be able to withstand during an earthquake. In mining or seismological context ppv is commonly used because most seismic monitoring systems measure ppv (www.scotland. gov.uk). 
Scaling laws can be established to estimate seismic induced damage based on dynamic stress concentration. A scaling law (Eqn 3) relating event magnitude ( $M_{N}$ on Nuttli scale), $p p v(\mathrm{~m} / \mathrm{s})$ and distance to event $(R$ in metres) was established from data from Canadian mines (Kaiser et al., 1996):

$$
p p v=\frac{c^{*} 10^{a^{*}\left(M_{N}+1\right)}}{R}
$$

For Creighton Mine, Kaiser et al. (1996) determined constants $\mathrm{a}^{*}$ and $\mathrm{c}^{*}$ as 0.3 and 0.5 , respectively. Fig. 16 shows the corresponding relationship between $M_{N} R$ and $p p v$. The equivalent maximum induced stress change $\Delta \sigma^{d}{ }_{m a x}$ at the excavation wall ranges from $\sim 50 \mathrm{MPa}$ (for $\mathrm{ppv}=3 \mathrm{~m} / \mathrm{s}$ ) to $\sim 1$ $\mathrm{MPa}($ at $\mathrm{ppv}=0.03 \mathrm{~m} / \mathrm{s})$.

Locations with seismically induced damage are plotted in Fig. 16 and were used to calibrate the approach described above and then used to establish hazard maps (note: some are related to stress others to shakedown).

\section{SEISMIC HAZARD MAPS}

The objective of monitoring seismicity at mines is to enhance worker safety and to reduce risk in general, e.g., to minimize production interruptions. These goals can be achieved by various means, all involving some form of data analysis to produce practically useful outputs (e.g., re-entry policies, stoping sequences, etc.). Here we focus on means to identify hazards related to infrastructure, i.e., the development of hazard maps.

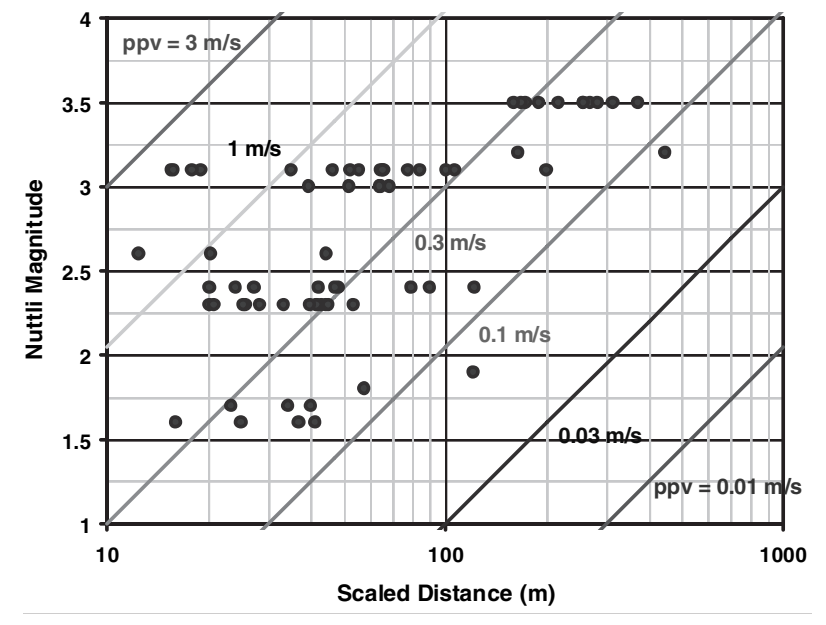

FIG. 16 Ground motion intensity chart for site-specific parameters; locations experiencing damage to excavations are also shown

Hazard maps provide an overall picture of the stability conditions in a mine for planning and operational control purposes. They show hazardous areas in the mine by identifying degraded rockmass zones, seismically active structures such as faults, and areas of high impact by seismic waves (dynamic stressing). Degraded zones of rock, if close to excavations and infrastructure crossing seismically active planes or active fault zones will require higher support levels and mining sequences must be properly managed to minimize impact on hazardous areas. When planning, new mine infrastructure may be located outside hazardous zones if this is economically acceptable.
In this study, three hazard factors were used to develop hazard maps:

- MS degradation with MS density as an indicator of level of rockmass degradation

- Seismically active planes as indicators of both localized rockmass degradation and rockbursts source potential

- Dynamic loading due to seismic stress

More factors will be included in the future.

\subsection{MS Degradation Hazard}

The space-time density procedure was used to define four density levels shown in Table 3. The four MS density levels correspond to four hazard levels due to reductions in rockmass quality RMR (Bieniawski, 1973).

TABLE 3 Site-specific hazard rating of MS degradation factor (ratings must be calibrated at each mine)

\begin{tabular}{lcccc}
\hline $\begin{array}{l}\text { No. of MS } \\
\text { events, } \\
\mathbf{R = 5 m}\end{array}$ & $\begin{array}{c}\text { Change in RMR } \\
\begin{array}{l}\text { RMR (from } \\
\text { RMR }=\mathbf{8 5} \text { ) }\end{array}\end{array}$ & Rating & UCS $_{\mathrm{rm}}$ & $\begin{array}{c}\text { Hazard } \\
\text { impact }\end{array}$ \\
\hline$<5$ & 0 & Very Good & 100 & Negligible \\
$5-10$ & -15 & Good & 40 & Low \\
$10-50$ & -25 & Fair & 20 & Moderate \\
$\geq 50$ & -35 & Fair to Poor & 10 & High \\
\hline
\end{tabular}

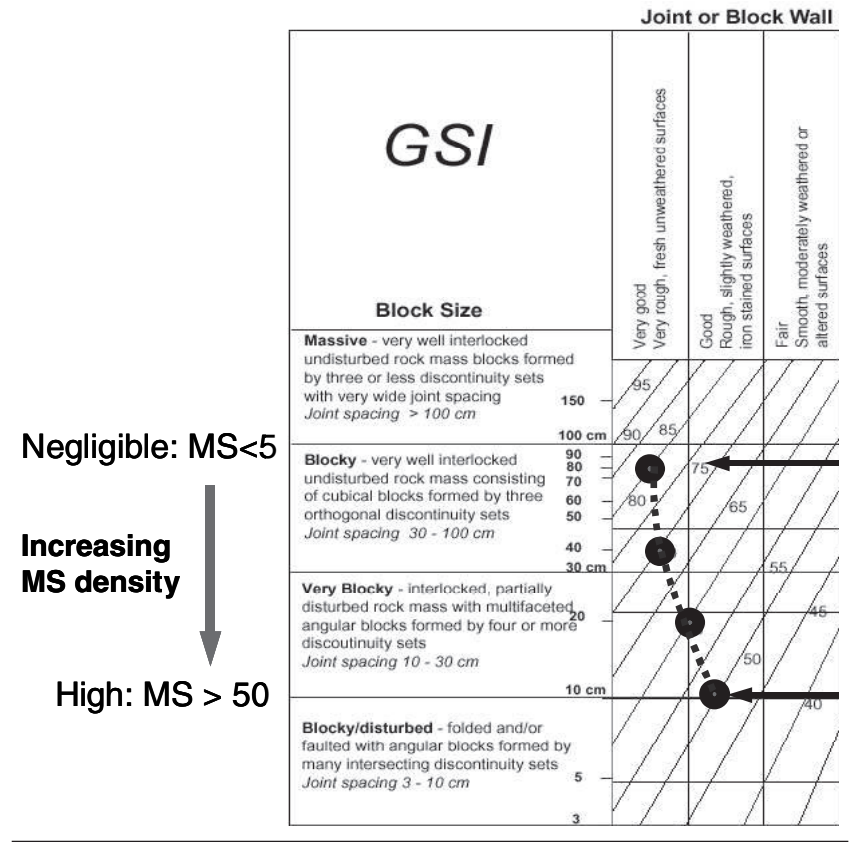

FIG. 17 Effect of increasing MS degradation on rockmass quality

Increasing MS or induced fracture density levels causing rockmass degradation can be primarily viewed as a gradual reduction in block size. This is illustrated schematically in Fig. 17 by example on the Geological Strength Index (GSI) chart (Hoek et al., 1995; Cai and Kaiser, 2003).

In this manner, the degradation process and impact on critical infrastructure can be visualized as shown in four time windows by Fig. 18. This figure clearly shows how infrastructure is gradually impacted by rockmass degradation and where potentially additional rock support might have to be placed. 


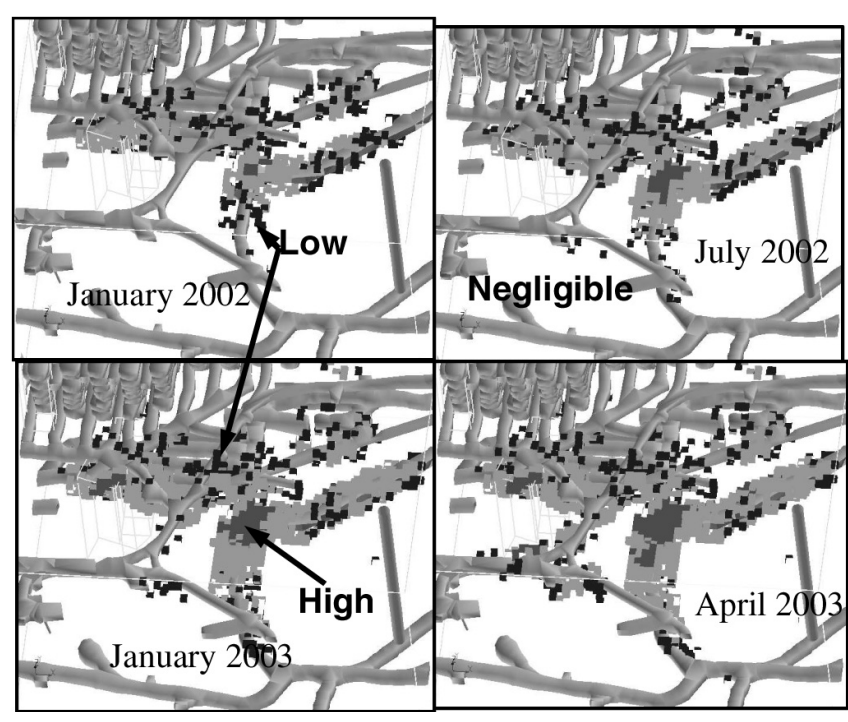

FIG. 18 MS degradation hazard rating evolution

\subsection{Seismically Active Plane (SAP) Hazard}

The hazard posed by SAPs increases as degrees of freedom for movement increase and thus when SAPs interact amongst themselves and with excavations. The mere presence of SAPs alone is a sign of potential hazard. Discrete structures are often signs of loosening as reflected in the stress reduction factor SRF in the Q-system (Barton et al., 1974). When SAPs intersect near an excavation, wedges or wedge-like structures may form and thus increase the hazard for falls of ground.

The hazard posed by the SAPs can be viewed as short to medium-term and represents a tendency of planes to slip or wedges to form. The SAPs may be discrete features or zones of ubiquitous fracturing. Generally, the higher the numbers of planes present at one location in the rockmass, the higher the hazard for drift instability, but also for fault-slip type movement (or rockbursting). Hence, the intersection lines of SAPs provide a means to rate and locate the hazard levels due to localized seismic activity. The intersection lines corresponding to Fig. 13 are shown as in Fig. 19.

If the active planes are considered as analogous to zones of (ubiquitous) joints, then the hazard levels can be estimated using the joint set number $\left(\mathrm{J}_{\mathrm{n}}\right)$ in the tunnelling quality index or Q-system (Barton et al., 1974) (Eqn 4). Increasing $J_{n}$ indicates reduction in $\mathrm{Q}$ and implies an increasing degree of freedom for block movement, hence, increasing hazard.

$$
Q=\frac{R Q D}{J_{n}} \bullet \frac{J_{r}}{J_{a}} \bullet \frac{J_{w}}{S R F}
$$

where RQD is the rock quality designation, $J_{n}$ joint set number, $\mathrm{J}_{\mathrm{a}}$ the joint alteration number, $\mathrm{J}_{\mathrm{w}}$ joint water reduction factor and SRF stress reduction factor. Table 4 shows the assumed relationship between number of joint sets and their equivalency in terms of SAPs and the adopted hazard impact rating.

These hazard impact ratings have been painted on drifts or other mine infrastructure in Fig. 19. Similar hazard maps can be generated using active planes or faults numbers or $S R F$ ratings. Again, visualisation of this nature provides an immediate image of potential hazard locations. This provides the ground control engineer a tool to focus inspection and possibly support rehabilitation efforts.
TABLE 4 Hazard rating for SAPs

\begin{tabular}{cccc|cc}
\hline $\begin{array}{c}\text { No. of } \\
\text { joint sets }\end{array}$ & $\begin{array}{c}\text { Equivalent No. } \\
\text { of SAPs }\end{array}$ & Jn & $\begin{array}{c}\text { Impact } \\
\text { rating }\end{array}$ & $\begin{array}{c}\text { Faults } \\
\text { faults }\end{array}$ & SRF \\
\hline Random & Random & 1 & Negligible & 0 & 1 \\
\hline 1 & Close to a SAP & 2 & Low & 1 & 2.5 \\
\hline $\begin{array}{c}1+ \\
\text { random }\end{array}$ & $\begin{array}{c}\text { 1SAP } \\
\text { intersecting }\end{array}$ & 3 & Moderate & 2 & 5 \\
\hline $\begin{array}{c}2+ \\
\text { random }\end{array}$ & $\begin{array}{c}\text { At least 2 SAPs } \\
\text { intersecting }\end{array}$ & 6 & High & $\geq 3$ & 7.5 \\
\hline
\end{tabular}

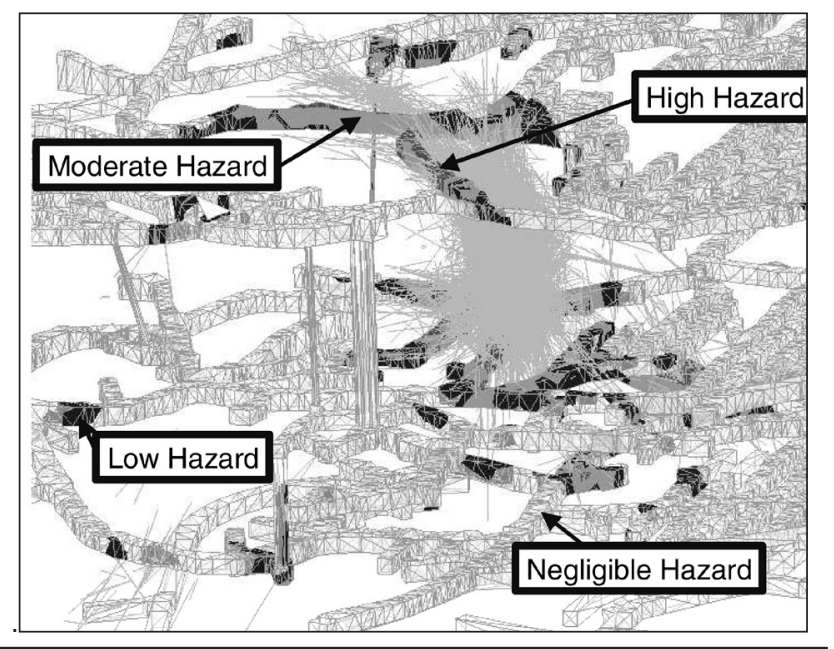

FIG. 19 Active planes impact rating assuming, planes are ubiquitous joints.

TABLE 5 Dynamic stress hazard rating

\begin{tabular}{lcccc}
\hline \multirow{2}{*}{ Hazard factor } & Negligible & Low & Moderate & High \\
\hline Seismicity $\mathrm{ppv}(\mathrm{m} / \mathrm{s})$ & $<0.1$ & $0.1-0.3$ & $0.3-1$ & $\geq 1$ \\
\hline $\begin{array}{l}\text { Dynamic stress } \\
\text { equivalent } \Delta \sigma^{d}(\mathrm{MPa})\end{array}$ & $<3$ & $3-10$ & $10-32$ & $\geq 32$ \\
\hline
\end{tabular}

\subsection{Dynamic Stress Hazard}

Table 5 presents the adopted dynamic stress impact rating and indicates the dynamic stress equivalents.

Fig. 20 presents a typical dynamic stress impact hazard map for a seismicity threshold at 3.5-Nuttli magnitude. The figure shows the iso-surface containing historical events exceeding the threshold and the corresponding hazard levels on two selected sections in the mine. Again, visualisation assists in identifying potentially hazardous locations.

\subsection{Combining Individual Hazards to Form Overall Hazard Maps}

The previously described individual hazards do not act independently and it is thus necessary to combine hazards to account for all possible hazard factors at a given location. Such maps should show effects of individual factors as well as the combined hazard.

A hazard map accounting for MS degradation, SAPs and stress effects is shown in Fig. 21. Table 6 shows the rating of the individual hazard factors and preliminary, combined hazard factor ratings used in the development of this combined 


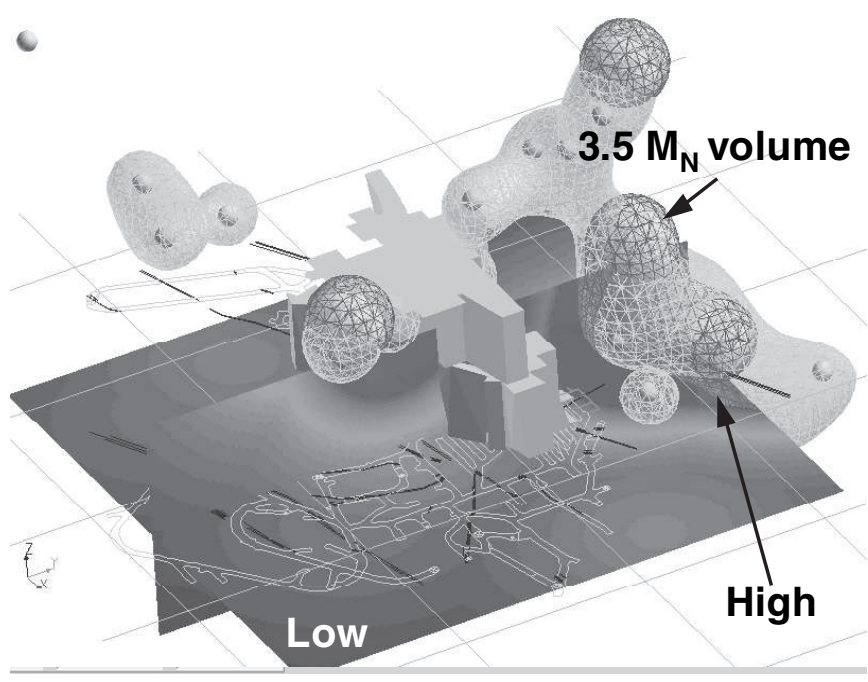

FIG. 20 Stress hazard map for a threshold at 3.5 Nuttli magnitude

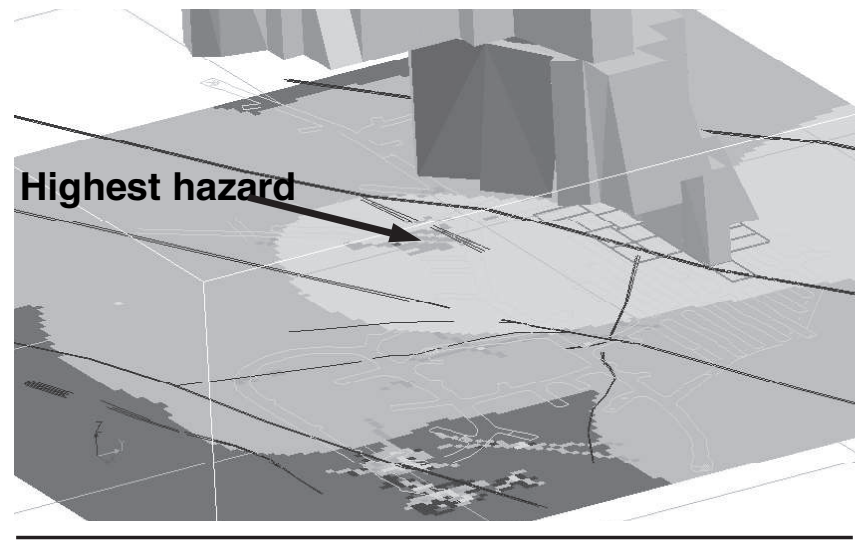

FIG. 21 Composite hazard map with 3.5 Nuttli magnitude event

TABLE 6 Preliminary rating of combined hazard factors

\begin{tabular}{lllll}
\hline Hazard factor & \multicolumn{4}{l}{ Hazard rating description } \\
\hline MS degradation & Negligible $(\mathrm{N})$ & Low $(\mathrm{L})$ & Moderate $(\mathrm{M})$ & High $(\mathrm{H})$ \\
\hline SAPs & Negligible & Low & Moderate & High \\
\hline Dynamic stress & Negligible & Low & Moderate & High \\
\hline $\begin{array}{l}\text { Hazard rating } \\
\text { weighting }\end{array}$ & 0 & 1 & 2 & 3 \\
\hline
\end{tabular}

TABLE 7 Preliminary composite hazard ranking matrix

\begin{tabular}{|c|c|c|c|}
\hline \multicolumn{2}{|c|}{$\begin{array}{l}\text { Combined impact } \\
\text { rating description }\end{array}$} & \multirow{2}{*}{$\begin{array}{l}\text { Combined ratings } \\
(\mathrm{N}, \mathrm{N}, \mathrm{N})\end{array}$} & \multirow{2}{*}{$\begin{array}{l}\text { Hazard } \\
\text { ranking }\end{array}$} \\
\hline Negligible & 1 & & \\
\hline & $2 a$ & $(\mathrm{~L}, \mathrm{~N}, \mathrm{~N})$ & 2 \\
\hline \multirow[t]{3}{*}{ Low } & $2 b$ & $(\mathrm{~L}, \mathrm{~N}, \mathrm{~N})$ & 3 \\
\hline & $2 c$ & $(\mathrm{~L}, \mathrm{~L}, \mathrm{~N})$ & 4 \\
\hline & $3 a$ & {$[\mathrm{M},(\mathrm{L}$ or $\mathrm{N}),(\mathrm{L}$ or $\mathrm{N})]$} & 5 \\
\hline \multirow[t]{3}{*}{ Moderate } & $3 b$ & {$[\mathrm{M}, \mathrm{M},(\mathrm{L}$ or $\mathrm{N})]$} & 6 \\
\hline & $3 c$ & $(\mathrm{M}, \mathrm{M}, \mathrm{M})$ & 7 \\
\hline & $4 a$ & {$[\mathrm{H},(\mathrm{N}, \mathrm{L}$ or $\mathrm{M}),(\mathrm{N}, \mathrm{L}$ or $\mathrm{M})]$} & 8 \\
\hline \multirow[t]{2}{*}{ High } & $4 b$ & {$[\mathrm{H}, \mathrm{H},(\mathrm{N}, \mathrm{L}$, or $\mathrm{M})]$} & 9 \\
\hline & $4 c$ & $(\mathrm{H}, \mathrm{H}, \mathrm{H})$ & 10 \\
\hline
\end{tabular}

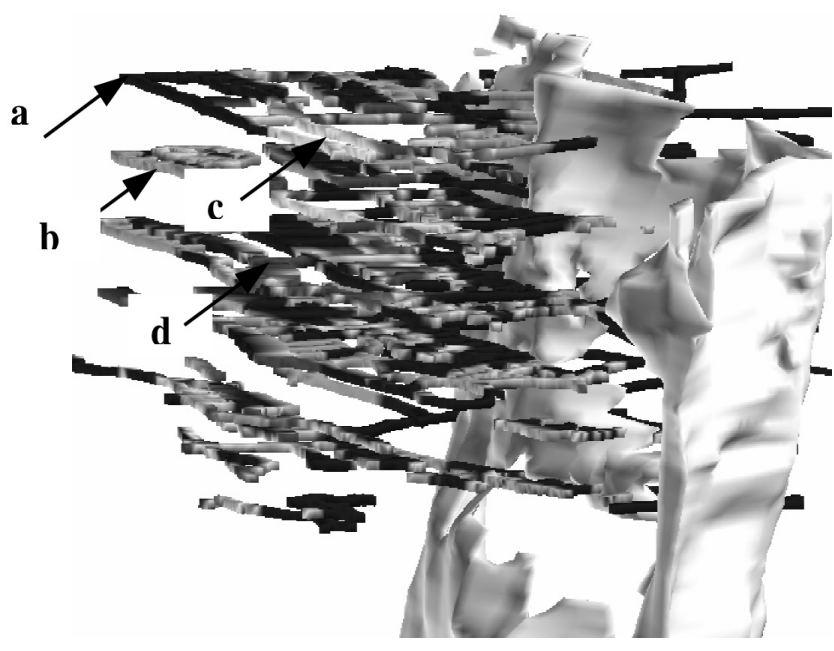

FIG. 22 Drifts@Risk visualisation by anticipated support type

hazard map. Table 7 provides the combined impact factor ratings. Four hazard levels are identified as 1 (Negligible) to 4 (High).

As indicated in the table headings, the proposed ratings are preliminary in nature. Further research and field calibration is required to verify and improve the rating system.

Nevertheless, Fig. 21 illustrates how the results of such a hazard assessment process can be visualized and quickly and effectively communicated to those working underground and making operational decisions. Since the maps can be up-dated in real time, they can also be used to guide reentry protocols. They can form an integral part of a sound emergency preparedness program.

The seismic hazard map concept and applications discussed above can be specifically applied to drifts. In assessing drift performance and support demand both stress and drift orientation (direction) are to be considered. Seismic hazard is an additional factor that can be added in burst prone grounds. The following section discusses a methodology for quickly identifying drifts at risk for both planning and rehabilitation purposes.

\section{DRIFTS AT RISK}

Support demand depends on a wide range of factors, including initial and induced stress conditions, stope geometry, mine sequencing, rockmass quality, geological domain characteristics, joint set properties and time. Seismicity is another factor that can be added as shown above. Typically, these factors will vary significantly across a given mining horizon.

To address the needs of industry, MIRARCO completed the first stage of a Drifts@Risk suite of tools for use in Laurentian University's VR facility. These tools encapsulate some of the research of the Geomechanics Research Centre on geomechanics mine design during the last decade. The Drifts@Risk modules enable engineering, geology and production teams to apply these techniques in a matter of minutes allowing comparisons with visual or quantitative field observations.

Drifts@Risk is a wizard developed to assess stress- (depthof-failure) and wedge-related instability of mine drifts. Drift geometry, geological structures, and results from stress analyses are combined to determine risk levels (Drifts@Risk) and then visualized in a similar manner to hazard maps; except, in this case, the drifts are painted according to the anticipated support (as defined below) rather than hazard type (Fig. 22): 
- less than standard support required (LS) - a

- standard support adequate (SS) - b

- rehabilitation anticipated and heavy support (HS) required - $\mathrm{c}$

- rockburst potential high; special burst-resistant support recommended (RS) - d

Drifts@Risk allows mine engineers to evaluate several aspects of geomechanics design of an orebody, including:

- Placement of infrastructure: facilitated by quick means to evaluate geomechanics influences in an interactive manner within a VR framework.

- Support selection: based on selected site-specific geomechanics constraints, the portion of the total drift lengths that fall into pre-defined Risk Level categories can be determined (Feet@Risk). This is illustrated by Fig. 23 for a drift affected by mining nearby stopes in 8 mining steps. Heavy spalling and some rockbursting are immediately anticipated. As mining progresses, the length of drift affected by bursting grows to about $70 \mathrm{~m}$ in mining step 2 . After step 3 significant yielding is anticipated, requiring deformable support over a length of about 140m.

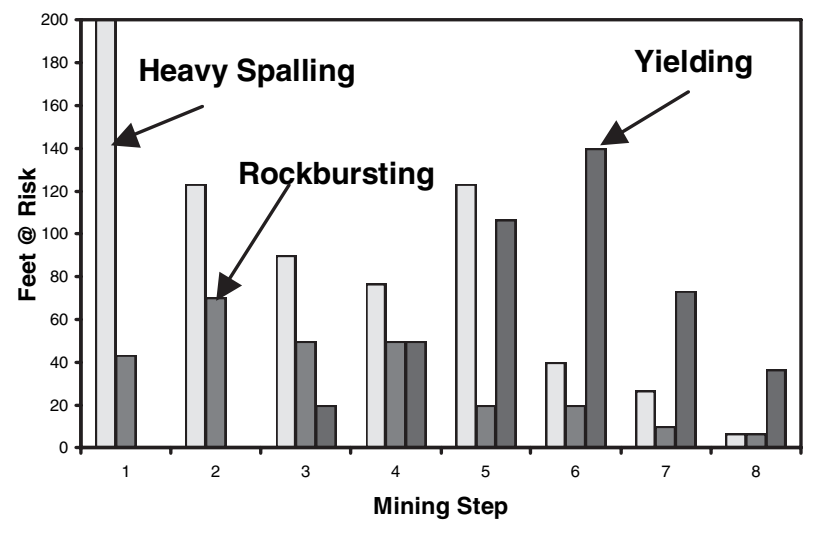

FIG. 23 Feet@risk (see below) as mining passes drift (Alcott et al. 1999)

- Support costing: based on support chosen for anticipated hazard types and levels.

Traditionally, many mine operations have relied on a systematic, standardized support design approach, which tends to over-look variability on support demand. As a result, sections of the drift may be over-supported (conservative design) whereas other sections may be inadequately supported for long-term demand (costly rehabilitation may be required).

To assist in support design, a Feet@Risk module was developed which builds on Drifts@Risk stability results. The Feet@Risk analyzer determines the portion of the total drift length that fall into predefined Risk Level categories (representing a range of support-type categories), the selection of which is dictated by combinations of stress damage or wedge failure characteristics (and possible seismicity in burstprone mines). The support categories are painted onto the infrastructure, as illustrated by Fig. 22, to visualize support requirements along the drift. The resulting images can then be utilized by the ground control staff during underground inspection to first calibrate the approach and then assist in evaluating local risk levels and support requirements.

A support category analysis for one of the levels in Fig. 22 is presented in Fig. 24. The anticipated support and rehabilitation costs can readily be determined based on such information by multiplying lengths by support costs for each support type. Comparisons between two levels showed that the support costs (for initial installation only) for a favourable layout was about $\$ 400,000$ lower than for a level with a less favourable layout.

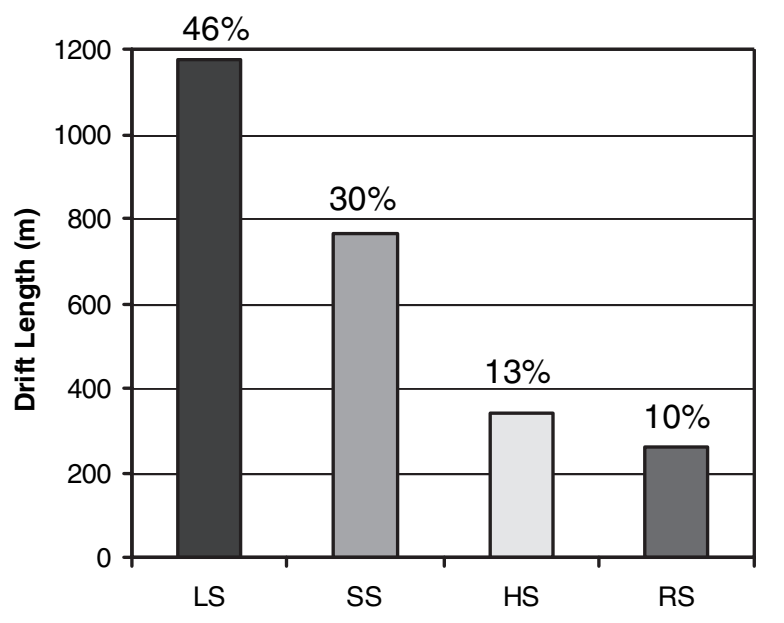

FIG. 24 Feet@Risk based on Drift@Risk procedure (Henning et al., 2003)

Scheduling of development and advance rate estimates can be optimized considering total lengths of drift requiring a specific support type and timing within the production schedule.

The benefits of such integrated data analyses procedures can be significant, including less over-support, reduced rehabilitation demand, and improved budgeting of material and labour expense. Worker safety is also enhanced as potential hazards can be proactively avoided.

\section{CONCLUDING REMARKS}

3D virtual reality visualisation has become a critical element of integrated data processing. As illustrated above, visualisation combined with mine modelling, integrating complex mining-induced stress fields, rockmass variability (geology and structures), cumulative microseismicity effects, that alters the virgin rockmass, and effects of seismicity, allows us today to gain critical insight into the response of an orebody to increasing levels of extraction. It allows us to identify and understand the evolution pattern of rockmass degradation, the mobilization of weakness zones (seismically active planes), time-links in seismic patterns, and their distribution and impact on operations (hazard levels).

With 3D VR, we have succeeded in advancing our understanding of the complex nature of microseismic and seismic event migration. VR combined with an appropriate software environment allows us to fuse large volumes of data and to visualize what normally is presented in graphs and tables and thus only accessible to the patient reader or the expert. By presenting geomechanics data in a visual form, communication is enhanced and miners, engineers and management can simultaneously understand the result of advanced science and engineering.

The ability to rapidly integrate complex data sets and to analyse them visually has enabled us to develop procedures and tools that offer new dimensions in the interpretation of seismic data. It has also allowed us to calibrate models more effectively and to translate research results into practically useful tools. 
The benefits of these new techniques to a mine are significant:

- in locating critical mine structures (detailed layout design)

- in making preventative support decision and in prioritizing of support logistics

- in enhancing workplace safety by identify hazardous areas in space and time and in developing advanced re-entry policies

- in real-time processing of seismic data to implement such policies as part of emergency preparedness and due-diligence procedures.

Future work aims at incorporating other hazard factors and at the development of risk maps. Risk assessment requires knowledge of factors of safety, which require a handle on both demand and capacity. Hence, it will be necessary to introduce factors that relate to the self-supporting capacity of the rock (rockmass quality) and to the capacity of the support (Support element capacities and behaviour as well as support condition). In this manner, we will eventually, be able to manage risk in a well-informed manner and assess the cost / benefit of both support and mining practices better.

\section{ACKNOWLEDGMENT}

The research work would not have been possible without the support of INCO Ltd., particularly the INCO Mines Technology Department and Creighton Mine. Special thanks are directed to:Steve Wood, Larry Lauzon, AlPunkkinen, Chris Meandro, Steve Audette and Dr. Robert Tan from Creighton Mine; Brian Maynard, Samantha Espley and Robert Barclay from the INCO Mines Technology Department. Additional support was provided through the following agencies: the Northern Ontario Heritage Fund Corp. (NOHFCo), The Natural Sciences and Engineering Research Council (NSERC) the Ontario Research and Development Fund (OR\&DCF), and the Canada Foundation for Innovation (CFI)/ Ontario Innovation Trust (OIT). In addition to the co-authors many current and former students and staff of MIRARCO have contributed to this research and are thankfully acknowledged: B. Anderson, J. Alcott, L. Cotesta, A. Dasys, V. Falmagne, J. Henning, A. Verma and many more.

\section{REFERENCES}

Alcott, J.M., Kaiser, P.K., Gauthier, M., Nelson, D. and Mah, P. (1999) SHARK Stability Hazard and Risk Assessment at Placer Dome's Campbell Mine. Colloque de Contrôle de Terrain, Val-d'Or, 9 p.

Barton, N., Lien, R. and Lunde, J. (1974) Engineering classification of jointed rockmasses for the design of tunnel support. Rock Mech. 6, pp. 189-236.

Bawden, W.F. and Coulson, A.L. (1993) Structural and geomechanical study of Creighton Mine with increased attention focused on the levels below the 6600 level. Rept. No. MD005, Queen's University, Kingston.

Bieniawski, Z.T. (1973) Engineering classification of rockmasses. Trans. S. African Institute of Civil Eng. 15, pp. 335-344.

Cai, M., Kaiser, P.K., Uno, H., Tasaka, Y. and Minami, M. (2003) Estimating rockmass strength and deformation modulus using GSI system - a quantitative approach. Int. J. Rock Mech. Min. Sci., 41(1), pp. 3-29.

ESG (2000) Engineering Seismology Group -Validation of real-time source parameter calculation at Creighton Mine, Sudbury, Canada. Report Submitted to Inco Mines Research and Mining Research Directorate of Canada, Report \#ESGQN95-01, 22 p

Falmagne, V. (2001) Rockmass degradation and microseismicity, Ph.D. thesis, Department of Mining Engineering, Queen's and in Collaboration with School of Engineering at Laurentian University, Sudbury, Ontario, Canada, $401 \mathrm{p}$.

Falmagne, V., Kaiser, P.K. and Martin, C.D. (1998) Microseismic monitoring and rockmass degradation. In CD-ROM Proc 100th Canadian Institute of Mining, Metallurgy and Petroleum publications, Montreal, $8 \mathrm{p}$.

Fröhlich, B. and Göbel, M. (1999) Virtual reality in the oil and gas industry. In ERCIM News 37, Online Edition.Fröhlich, B. and M. Göbel, 1999. Virtual reality for oil and gas industry. ERCIM News, Online Edition.
Henning, J.G., Cotesta, L. and Kaiser, P.K. (2003) Geomechanics Design of Underground Excavations Utilizing Virtual Reality. In Proceedings, 4th International Conference on Computer Applications in the Minerals Industries (CAMI), 8-10 September 2003, Calgary, Alberta.

Hoek, E., Kaiser, P.K. and Bawden, W.F. (1995) Support of underground excavations in hard rock. A.A. Balkema, Rotterdam.

Johnson, R.A. and Wichern, D.W. (1992) Applied multivariate statistics. Englewood Cliffs, NJ, Prentice-Hall, 642 p.

Kaiser, P.K., McCreath, D.R., and Tannant, D.D. (1996) Canadian rockburst support handbook. Geomechanics Research Centre, Laurentian University, Sudbury, Ontario, Canada.

Norsk Hydro (2003) Case study: Inside reality 3D virtual reality technology. In Schlumberger Information Systems: www.sis.slb.com.

Polyakov, V. (1999) Virtual reality in the oil and gas industry. In ERCIM News 37, Online Edition: SEED.

Schlumberger, F.E., Volz, W., Dorn, G., Fröhlich, B. and Roberts, D.M. (2002) Future trends in oil and gas visualisation. In Proceedings of the Conference on Visualisation, Boston, Massachusetts, pp. 567-570

Sharma, S. and Judd, W.R. (1991) Underground opening damage from earthquakes. Engineering Geology 30, pp. 263-276.

Tyler, T. (2003) Q\&A Roundtable Editorial. In Virtual Roundtable of Leading Industry Experts: Visualisation, Vol. 5.

Vasak, P. and Thibodeau, D. (2003) Seismicity used to identify and monitor active weakness planes in relation to assessment. Paper presented at the eastern Section Annual Meeting, Seismological Society of America, 19-21 October, University of Toronto, Toronto, Ontario, Canada.

Vasak, P., Suorineni, F.T., Kaiser, P.K. and Thibodeau, D. (2004) Hazard Map Approach Using Space-time Clustering Analysis of Mining-induced Microseismicity. CIM- AGM, Edmonton.

Vasak, P., Suorineni, F.T. and Verma, A. (2004) Identification of seismically active structures for hazard assessment at Creighton Mine. Report Submitted to INCO Mines Technology Department.

Vasak, P. and Neumann, M. (1999) Full-waveform microseismic monitoring. Report Submitted to Technical Advisory Committee, CAMIRO Mining Division, Rept \#11, 109 p.

Ward, J.H. (1963) Hierarchical grouping to optimize an objective function. J. Am. Stat. Assoc: 58, pp. 236-244.

www.archive.ncsa.uiuc.edu

www.eqhazmaps.usgs.gov

www.scotland.gov.uk

www.seed.slb

Zeitlin, M.J. (2003) In Virtual Roundtable of Leading Industry Experts: Vol. 5. 